\title{
Clinical efficacy and mechanism of Pralatrexate combined with Palbociclib Isethionate in treatment of bladder cancer patients
}

\author{
XIAOBIN WANG ${ }^{1}$, HUIHAN WANG ${ }^{2}$ and YONGSHENG SONG ${ }^{1}$ \\ Departments of ${ }^{1}$ Urinary Surgery (II) and ${ }^{2}$ Hematology (II), Shengjing Hospital of \\ China Medical University, Shenyang, Liaoning 110004, P.R. China
}

Received June 21, 2018; Accepted September 27, 2018

DOI: $10.3892 / \mathrm{ol} .2018 .9617$

\begin{abstract}
The clinical efficacy and mechanism of Pralatrexate (PTX) combined with Palbociclib Isethionate (PAL) in the treatment of bladder cancer patients was investigated. A retrospective analysis of medical records of 82 bladder cancer patients admitted to Shengjing Hospital of China Medical University from February 2015 to February 2018 was performed. Patients treated with PTX combined with PAL served as study group (42 cases) and patients with conventional GC (gemcitabine plus cisplatin) chemotherapy regimen were the control group (40 cases). Changes in liver function indexes before and after treatment were observed, including alanine aminotransferase (ALT), aspartate aminotransferase (AST), alkaline phosphatase (ALP), and total bilirubin (TBil). RT-qPCR was used for detection of relative expression levels of serum dihydrofolate reductase (DHFR) and vascular endothelial growth factor (VEGF) before and after treatment in the two groups. The clinical efficacy after treatment and adverse reactions during treatment were observed in the two groups. There was no significant difference in the clinical remission rate (RR) nor in the serum ALT, AST, ALP and TBil levels between the study and the control groups $(\mathrm{P}>0.05)$. Concentrations of serum ALT, AST, ALP and TBil were significantly higher than those before treatment in both groups $(\mathrm{P}<0.05)$. Serum ALT, AST, ALP and TBil concentrations in study group were significantly lower than those in control group $(\mathrm{P}<0.05)$. There was no significant difference in the incidence of thrombocytopenia and leukopenia between the two groups $(\mathrm{P}>0.05)$. There was no significant difference in
\end{abstract}

Correspondence to: Dr Yongsheng Song, Department of Urinary Surgery (II), Shengjing Hospital of China Medical University, 36 Sanhao Street, Shenyang, Liaoning 110004, P.R. China

E-mail: srfqgt@163.com; songys@sj-hospital.org

Key words: bladder cancer, Pralatrex, Palbociclib Isethionate, combination therapy, dihydrofolate reductase, vascular endothelial growth factor relative expression levels of serum DHFR mRNA and VEGF mRNA before treatment between the study and control groups $(\mathrm{P}>0.05)$. Those after treatment were significantly lower than those before treatment in both groups $(\mathrm{P}<0.05)$, and those after treatment in study group were significantly lower than those in control group $(\mathrm{P}<0.05)$. PTX combined with PAL can reduce adverse reactions of nausea and vomiting and liver function impairment during treatment and suppress tumor neovascularization. This is achieved possibly by inhibiting expression levels of DHFR and VEGF, thereby killing cancer cells. PTX combined with PAL may become a new method for the treatment of bladder cancer patients. DHFR and VEGF are expected to become novel therapeutic targets for the treatment of bladder cancer.

\section{Introduction}

As one of the most common malignant tumors, incidence of bladder cancer ranks the 9th among all malignant tumors, among which, $30 \%$ of patients have muscular invasive bladder cancer (1). Bladder cancer has the characteristics of rapid progress and high degree of malignancy and high recurrence and mortality rates (2). Radical cystectomy can be used to effectively remove tumor lesions, but the postoperative recurrence rate is higher and adjuvant postoperative chemotherapy is usually needed (3). Postoperative chemotherapy can inhibit local recurrence and distant metastasis, so as to improve the overall survival of patients (4). The standard treatment method for bladder cancer is the clinical first-line chemotherapy GC (gemcitabine plus cisplatin). However, bladder cancer patients can easily develop drug resistance. As a result, chemotherapy is often ineffective in clinic (5). Therefore, new effective treatment methods are needed.

In recent years, anti-folic acid drugs have been widely used in treatment of malignant tumors (6). The most commonly used anti-folic acid drug is methotrexate (MTX), which can inhibit dihydrofolate reductase (DHFR) to block the synthesis of tetrahydrofolate (FH4). Blocked FH4 causes restricted transfer of one-carbon group during the synthesis of glycosides pyrimidine nucleotide and purine nucleon, and inhibits the synthesis of DNA (7). Single-agent MTX, as a chemotherapeutic drug, easily leads to the development of acquired 
drug resistance, so it is often used in combination with other drugs such as cell cycle inhibitor (8). Pralatrexate (PTX), an upgraded product of methotrexate, is a new anti-folic acid and anti-tumor drug that can effectively inhibit DHFR. It can also competitively inhibit folylpolyglutamate synthetase to block the synthesis of thymidine and other biomolecules that rely on single-carbon transfer, so as to affect the synthesis of DNA and promote apoptosis of tumor cells (9). Palbociclib isethionate (PAL) is an FDA-approved highly selective CDK4/6 and cell cycle inhibitor that can be used as a first-line drug for the treatment of HER2-negative, ER-positive breast cancer, colon cancer and lung cancer. It can also prolong the progressionfree survival of tumor patients (10). DHFR is a main drug target for anti-infective therapy and tumor chemotherapy, due to its close relationship with multidrug resistance in various tumors (11). Vascular endothelial growth factor (VEGF) is a serum marker that reflects the malignancy degree of tumors. VEGF can promote the proliferation of endothelial cells and neovascularization, thereby promoting the growth and metastasis of tumors (12).

At present, there is no report on the application of PTX combined with PAL in the treatment of bladder cancer. In this study, a retrospective analysis of medical records of 82 bladder cancer patients admitted to Shengjing Hospital of China Medical University (Shenyang, China) was performed. Our study investigated the clinical efficacy and mechanism of PTX combined with PAL in the treatment of bladder cancer patients.

\section{Materials and methods}

General information. A retrospective analysis of medical records of 82 bladder cancer patients admitted to Shengjing Hospital of China Medical University from February 2015 to February 2018 was performed. Patients treated with PTX combined with PAL served as study group (42 cases) and patients with conventional GC chemotherapy regimen as the control group (40 cases). There were 28 males and 14 females in the study group, with age ranged from 51 to 77 years and a mean age of $66.57 \pm 2.58$ years, course of disease range from 2 to 8 years, with a mean course of disease of $4.26 \pm 2.47$ years. Clinical stage: 24 cases of stage III and 18 cases of stage IV; tumor distribution location: 11 cases of lateral wall of bladder, 19 cases of anterior wall and 12 cases of posterior wall. There were 29 males and 11 females in control group, aged from 53 to 79 years, with a mean age of $67.21 \pm 3.27$ years, course of disease ranged from 3 to 7 years, with a mean course of disease of $4.76 \pm 3.08$ years. Clinical stage: 21 cases of stage III and 19 cases of stage IV; tumor distribution location: 13 cases of lateral wall of bladder, 16 cases of anterior wall and 11 cases of posterior wall.

Inclusion and exclusion criteria. Inclusion criteria: confirmed as bladder cancer by pelvic CT, cystoscope biopsy and pathology (13); no contraindication to operation and treatment; no other history of tumor or radiotherapy and chemotherapy treatment; complete clinical data. This study was approved by the Ethics Committee of Shengjing Hospital of China Medical University. All participants signed informed consent. Exclusion criteria: those with neurological disorders; those with hematopoietic disorders and immune diseases; those with mental illness or a history of family psychosis.

Treatment methods. Control group was treated with a conventional GC chemotherapy regimen (14). Ondansetron (15) (Fuan Pharmaceutical Group Ningbo Team Pharmaceutical Co., Ltd., Ningbo, China; batch number: H10960146) was orally administered before chemotherapy to stop vomiting, $1,000 \mathrm{mg} / \mathrm{m}^{2}$ of gemcitabine (Harbin Gloria Pharmaceutical Co., Ltd., Harbin, China; batch number: H20040958) was infused intravenously for $2 \mathrm{~h}$ on the 1st, 8 th and 15th days of each cycle, and $30 \mathrm{mg} /$ $\mathrm{m}^{2}$ of cisplatin (Yunnan Gejiu Biological Pharmaceutical Co., Ltd., Yunnan, China; batch number: H53021740) was infused intravenously for $2 \mathrm{~h}$ on the $2 \mathrm{nd}$ day. A total of 4 cycles of chemotherapy was performed, 28 days for one cycle. Study group was treated with PTX combined with PAL. A total of 30 $\mathrm{mg} / \mathrm{m}^{2}$ of PTX injection (Allos Therapeutics Inc., Westminster, $\mathrm{CO}$, USA) was infused intravenously, 3 to $5 \mathrm{~min}$ each time, once a week. Six consecutive cycles were performed, 28 days for one cycle. After intravenous injection of PTX, $50 \mathrm{mg} / \mathrm{m}^{2}$ of PAL (Pfizer Pharmaceutical Co., Ltd., New York, NY, USA) was orally administered in study group once a week for 3 weeks, then treatment was stopped for 1 week. Six consecutive cycles were performed, 28 days for one cycle. Changes of neutrophils and platelets in the two groups were observed. If the neutrophil count was less than $1.0 \times 10^{9} \cdot \mathrm{L}^{-1}$, then recombinant human granulocyte colony-stimulating factor injection (Harbin Pharmaceutical Group Biological Engineering Co., Ltd., Harbin, China; batch number: S20000061) was administered, treatment was started when blood cells returned to normal. Treatment methods are shown in Table I.

Efficacy evaluation. Based on the evaluation criteria of solid tumor clinical treatment established by the World Health Organization (WHO) (16), clinical efficacy of study group and control group was evaluated and divided into four categories: complete remission (CR) the target lesion disappeared for $>4$ weeks and no new lesion was detected; partial remission (PR): after treatment, the target lesion gradually decreased in diameter, the reduction ratio of the diameter was $>50 \%$ compared with that before treatment, duration $>4$ weeks, and no new lesion was detected; stable disease (SD): target lesion gradually decreased in diameter, the reduction ratio of the diameter $<50 \%$ compared with that before treatment, and no new lesion was detected; progressive disease (PD): increase ratio of the diameter of the target lesion was $\geq 50 \%$ compared with that before treatment, and new lesion produced. CR and $\mathrm{PR}$ were clinically effective rates. Clinical response rate $(\mathrm{RR})=(\mathrm{CR}+\mathrm{PR}) /$ total number of cases $\mathrm{x} 100 \%$. Adverse reactions during treatment in study group and control group were observed. Main adverse reactions include thrombocytopenia, leukopenia, nausea and vomiting, and liver damage. Evaluation criteria for liver injury are based on the classification criteria for acute and subacute toxicity of antitumor drugs (17).

Indicator detection. Changes of liver function indexes were observed 1 day before treatment and 1 day after treatment. Venous blood $(5 \mathrm{ml})$ was taken and placed in a vacuum tube without anticoagulant. After the blood was coagulated, blood was placed in a centrifuge (Shanghai Luxiangyi Centrifuge 
Table I. Treatment methods.

Chemotherapy methods

Method of administration

GC chemotherapy

(Control group)

PTX+PAL chemotherapy

(Study group)
Oral administration of ondansetron before chemotherapy

Intravenous infusion of gemcitabine $\left(1,000 \mathrm{mg} / \mathrm{m}^{2}\right)$ for $2 \mathrm{~h}$ at 1,8 and 15 days

Intravenous infusion of cisplatin $\left(30 \mathrm{mg} / \mathrm{m}^{2}\right)$ for $2 \mathrm{~h}$ on the $2 \mathrm{nd}$ day

28 days for one cycle, totally 4 cycles

Intravenous infusion of PTX $\left(30 \mathrm{mg} / \mathrm{m}^{2}\right) 3-5 \mathrm{~min}$, once a week

Oral intake of PAL $\left(50 \mathrm{mg} / \mathrm{m}^{2}\right)$, once a week for 3 weeks, followed by stop for 1 week

28 days for one cycle, totally 6 consecutive cycles

Table II. Primer sequences.

\begin{tabular}{lll}
\hline Gene & \multicolumn{1}{c}{ Upstream } & \multicolumn{1}{c}{ Downstream } \\
\hline DHFR & 5'-TGGTTCGCTAAACTGCATCGT-3' & 5'-CAGGAATGGAGAACCAGGTCTTC-3' \\
VEGF & 5'-GAGTATATCTTCAAGCCGTCCTGT-3' & 5'-ATCTGCATAGTGACGTTGCTCTC-3' \\
U6 & 5'-CTCGCTTCGGCAGCACA-3' & 5'-AACGCTTCACGAATTTGCGT-3' \\
\hline
\end{tabular}

Instrument Co., Ltd., Shanghai, China) and centrifuged at $670.8 \mathrm{x} \mathrm{g}$ at $20-25^{\circ} \mathrm{C}$ for $10 \mathrm{~min}$ to separate serum. AU5800 automatic biochemical analyzer [Beckman Coulter Trading (China) Co., Ltd., Shanghai, China] was used to detect serum alanine aminotransferase (ALT), aspartate aminotransferase (AST), alkaline phosphatase (ALP) and total bilirubin (TBil). Kits were purchased from Beckman Coulter Trading (China) Co., Ltd., and the testing procedure was carried out with reference to the instructions of the manufacturers.

RT-qPCR was used to detect the relative expression of serum DHFR mRNA and VEGF mRNA in the 2 groups before treatment and 1 month after treatment. A total of $10 \mathrm{ml}$ fasting venous blood was extracted and placed in a vacuum tube without anticoagulant. Blood was centrifuged at $2000 \mathrm{rpm}$ for $10 \mathrm{~min}$ to separate the serum. Serum was stored in a $-80^{\circ} \mathrm{C}$ refrigerator (Wuxi Guanya Refrigeration Technology Co., Ltd., Wuxi, China) before use. Serum total RNA was extracted using TRIzol kit (ABI Corporation, Lee's Summit, MO, USA) according to manufacturer's instruction. Integrity of total RNA was determined by $1 \%$ agarose gel electrophoresis and RNA concentration was measured using a UV-Vis spectrophotometer (INESA Analytical instrument Co., Ltd.; Shanghai, China). Reverse transcription was performed using M-MLV reverse transcription kit (Beijing Shengkeboyuan Biotechnology Co., Ltd., Beijing, China). Reaction conditions: $45^{\circ} \mathrm{C}$ for $25 \mathrm{~min}$ and $80^{\circ} \mathrm{C}$ for $10 \mathrm{~min}$. The synthesized cDNA sample was stored at $-20^{\circ} \mathrm{C}$ before use. DHFR mRNA and VEGF mRNA fluorescent quantitative PCR kits were purchased from Invitrogen; Thermo Fisher Scientific, Inc. (Waltham, MA, USA), U6 was used as an endogenous control. Primers were designed and synthesized by Invitrogen; Thermo Fisher Scientific, Inc. (Table II). RT-qPCR (20 $\mu \mathrm{l}$ of total volume) reaction system: $10 \mu \mathrm{l}$ of SYBRGreen mix, $1 \mu 1$ of PCR primer mix, $5 \mu$ l of cDNA template diluted 10 -fold and $4 \mu \mathrm{l}$ of RNase free water. PCR reaction conditions:
Pre-denaturation at $94^{\circ} \mathrm{C}$ for $1 \mathrm{~min}$, followed by 35 cycles of denaturation at $95^{\circ} \mathrm{C}$ for $15 \mathrm{sec}$, annealing at $60^{\circ} \mathrm{C}$ for $20 \mathrm{sec}$ and extension at $72^{\circ} \mathrm{C}$ for $1 \mathrm{~min}$, and final extension at $72^{\circ} \mathrm{C}$ for $10 \mathrm{~min}$. PCR reactions were performed on ABI PRISM 7300 fluorescence quantitative PCR instrument (ABI Corporation) with U6 as endogenous control. Results were processed using $2^{-\Delta \Delta c q}$ method (18).

Statistical analysis. SPSS 19.0 [Yiyun (Shanghai) Information Technology Co., Ltd., Shanghai, China] was used for statistical analysis. Measurement data are expressed using mean \pm standard deviation. $t$-test was used for comparisons of data between groups, paired t-test was used for comparison between data before treatment and after treatment within the same group. Chi-square test was used for comparison of enumeration data between groups. $\mathrm{P}<0.05$ indicates the difference is statistically significant.

\section{Results}

Baseline data of study group and control group. There was no significant difference between study group and control group in general clinical baseline data such as sex, age, course of disease, histopathological type, pathological differentiation degree, tumor distribution location, clinical stage and existence of distant metastasis $(\mathrm{P}>0.05)$ (Table III).

Clinical efficacy of study group and control group. After treatment, there were 14 cases of CR (33.33\%), 8 cases of PR (19.05\%), 11 cases of SD (26.19\%), 9 cases of PD (21.43\%) and 22 cases of RR (52.38\%) in study group and 9 cases of CR (22.50\%), 8 cases of PR (20.00\%), 12 cases of SD (30.00\%), 11 cases of $\mathrm{PD}(27.50 \%)$ and 17 cases of RR (42.50\%) in control group. There was no significant difference in treatment RR between study group and control group ( $\mathrm{P}>0.05)$ (Table IV). 
Table III. Baseline data of study group and control group [n (\%)]/(mean \pm SD).

\begin{tabular}{|c|c|c|c|c|}
\hline Category & Study group $(\mathrm{n}=42)$ & Control group $(n=40)$ & $\mathrm{t} / \chi^{2}$ value & P-value \\
\hline Sex & & & 0.329 & 0.636 \\
\hline Male & $28(66.67)$ & $29(72.50)$ & & \\
\hline Female & $14(33.33)$ & $11(27.50)$ & & \\
\hline Age (years) & $66.57 \pm 2.58$ & $67.21 \pm 3.27$ & 0.986 & 0.326 \\
\hline Course of disease (years) & $4.26 \pm 2.47$ & $4.76 \pm 3.08$ & 0.812 & 0.418 \\
\hline Histopathological type & & & 0.965 & 0.611 \\
\hline Transitional cell carcinoma & $37(88.10)$ & $36(90.00)$ & & \\
\hline Squamous carcinoma & $1(2.38)$ & $2(5.00)$ & & \\
\hline Adenocarcinoma & $4(9.52)$ & $2(5.00)$ & & \\
\hline Pathological differentiation degree & & & 0.185 & 0.912 \\
\hline Well-differentiated & $14(33.33)$ & $12(30.00)$ & & \\
\hline Moderately differentiated & $19(45.24)$ & $18(45.00)$ & & \\
\hline Poorly differentiated & $9(21.43)$ & $10(25.00)$ & & \\
\hline Tumor distribution location & & & 0.419 & 0.811 \\
\hline Lateral wall of bladder & $11(26.19)$ & $13(32.50)$ & & \\
\hline Anterior wall & $19(45.24)$ & $16(40.00)$ & & \\
\hline Posterior wall & $12(28.57)$ & $11(27.50)$ & & \\
\hline Clinical stage & & & 0.178 & 0.825 \\
\hline Stage III & $24(57.14)$ & $21(52.50)$ & & \\
\hline Stage IV & $18(42.86)$ & $19(47.50)$ & & \\
\hline Distant metastasis & & & 1.279 & 0.322 \\
\hline Yes & $9(21.43)$ & $13(32.50)$ & & \\
\hline No & $33(78.57)$ & $27(67.50)$ & & \\
\hline Tumor size & & & 0.483 & 0.513 \\
\hline$\geq 3 \mathrm{~cm}$ & $22(52.38)$ & $24(60.00)$ & & \\
\hline$<3 \mathrm{~cm}$ & $20(47.62)$ & $16(40.00)$ & & \\
\hline
\end{tabular}

Table IV. Comparison of results of clinical efficacy between study group and control group [n (\%)].

\begin{tabular}{lcccc}
\hline Category & Study group $(\mathrm{n}=42)$ & Control group $(\mathrm{n}=40)$ & $\chi^{2}$ value & P-value \\
\hline CR & $14(33.33)$ & $9(22.50)$ & - & - \\
PR & $8(19.05)$ & $8(20.00)$ & - & - \\
SD & $11(26.19)$ & $12(30.00)$ & - & - \\
PD & $9(21.43)$ & $11(27.50)$ & - & - \\
RR & $22(52.38)$ & $17(42.50)$ & 0.802 & 0.387 \\
\hline
\end{tabular}

Changes in liver function indexes before and after treatment in study group and control group. Serum concentrations of ALT, AST, ALP and TBil in study group were not significantly different from those in control group $(\mathrm{P}>0.05)$. After treatment, serum ALT concentration of study group and control group was significantly higher than that before treatment $(\mathrm{t}=11.300$, $\mathrm{P}<0.001 ; \mathrm{t}=14.570, \mathrm{P}<0.001)$, and serum AST concentration $(\mathrm{t}=20.220, \mathrm{P}<0.001 ; \mathrm{t}=22.510, \mathrm{P}<0.001)$, serum ALP concentration $(\mathrm{t}=15.68, \mathrm{P}<0.001 ; \mathrm{t}=19.190, \mathrm{P}<0.001)$, and serum TBil concentration $(t=12.720, \mathrm{P}<0.001 ; \mathrm{t}=20.080, \mathrm{P}<0.001)$ were significantly higher than before treatment. After treatment, serum ALT, AST, ALP, and TBil concentrations in study group were significantly lower than those in control group $(\mathrm{t}=3.536$, $\mathrm{P}<0.001 ; \mathrm{t}=3.541, \mathrm{P}<0.001 ; \mathrm{t}=7.276, \mathrm{P}<0.001$ ) (Table V).

Treatment of adverse reactions in study group and control group. Common adverse reactions in study group and control group were thrombocytopenia, leukopenia, nausea and vomiting and liver function impairment. Study group had 6 cases of thrombocytopenia (14.29\%), 19 cases of leucopenia (45.24\%), 15 cases of nausea and vomiting (35.71\%) and 3 cases of liver function impairment $(7.14 \%)$. The control group showed 4 cases of thrombocytopenia (10.00\%), 16 cases of leukopenia (40.00\%), 22 cases of nausea and vomiting 
Table V. Changes in liver function indexes before and after treatment in the study group and the control group (mean \pm SD).

\begin{tabular}{|c|c|c|c|c|c|c|c|c|}
\hline \multirow[b]{2}{*}{ Indexes } & \multicolumn{2}{|c|}{ Study group $(n=42)$} & \multirow[b]{2}{*}{$\mathrm{t}$ value } & \multirow[b]{2}{*}{ P-value } & \multicolumn{2}{|c|}{ Control group $(n=40)$} & \multirow[b]{2}{*}{$\mathrm{t}$ value } & \multirow[b]{2}{*}{ P-value } \\
\hline & Before treatment & After treatment & & & Before treatment & After treatment & & \\
\hline $\operatorname{ALT}(\mathrm{U} / \mathrm{l})$ & $23.17 \pm 5.03$ & $35.91 \pm 5.18^{\mathrm{a}, \mathrm{b}}$ & 11.300 & $<0.001$ & $22.89 \pm 5.28$ & $40.03 \pm 5.37^{c}$ & 14.570 & $<0.001$ \\
\hline $\operatorname{AST}(\mathrm{U} / 1)$ & $20.13 \pm 2.17$ & $35.48 \pm 4.39^{\mathrm{a}, \mathrm{b}}$ & 20.220 & $<0.001$ & $19.87 \pm 2.23$ & $38.98 \pm 4.56^{\mathrm{c}}$ & 22.510 & $<0.001$ \\
\hline $\operatorname{ALP}(\mathrm{U} / \mathrm{l})$ & $66.29 \pm 9.37$ & $110.13 \pm 15.37^{\mathrm{a}, \mathrm{b}}$ & 15.68 & $<0.001$ & $66.47 \pm 9.03$ & $119.51 \pm 14.97^{\mathrm{c}}$ & 19.190 & $<0.001$ \\
\hline TBil $(\mu \mathrm{mol} / \mathrm{l})$ & $10.58 \pm 1.33$ & $14.25 \pm 1.28^{\mathrm{a}, \mathrm{b}}$ & 12.720 & $<0.001$ & $10.34 \pm 1.24$ & $16.47 \pm 1.48^{\mathrm{c}}$ & 20.080 & $<0.001$ \\
\hline
\end{tabular}

${ }^{a} \mathrm{P}<0.001$, compared with control group after treatment. ${ }^{b} \mathrm{P}<0.001$, compared with study group before treatment. ${ }^{\mathrm{c}} \mathrm{P}<0.001$, compared with control group before treatment.

Table VI. Comparison of results of treatment of adverse reactions between study group and control group [n (\%)].

\begin{tabular}{lccr}
\hline Category & Study group $(\mathrm{n}=42)$ & Control group $(\mathrm{n}=40)$ & $\chi^{2}$ value \\
\hline Thrombocytopenia & $6(14.29)$ & $4(10.00)$ & 0.799 \\
Leukopenia & $19(45.24)$ & $16(40.00)$ & 0.230 \\
Nausea and vomiting & $15(35.71)$ & $22(55.00)$ & 4.843 \\
Liver function impairment & $3(7.14)$ & $10(25.00)$ & 4.897 \\
\hline
\end{tabular}

A

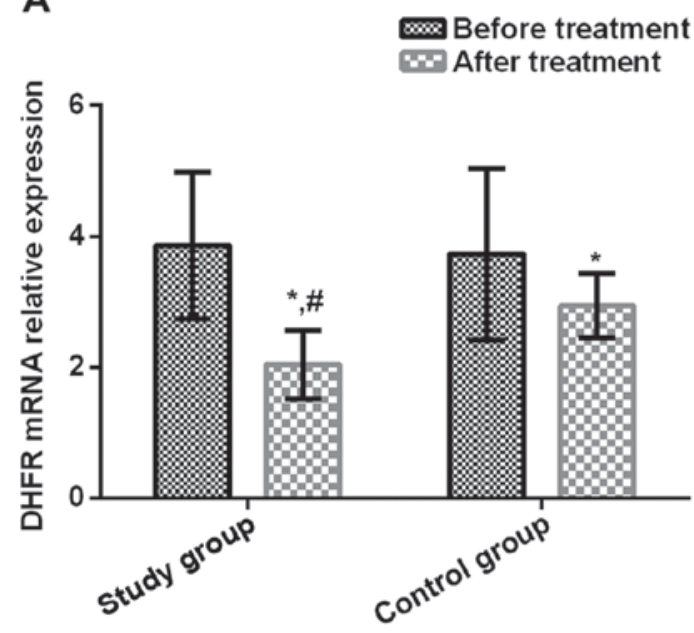

$\mathbf{B}$

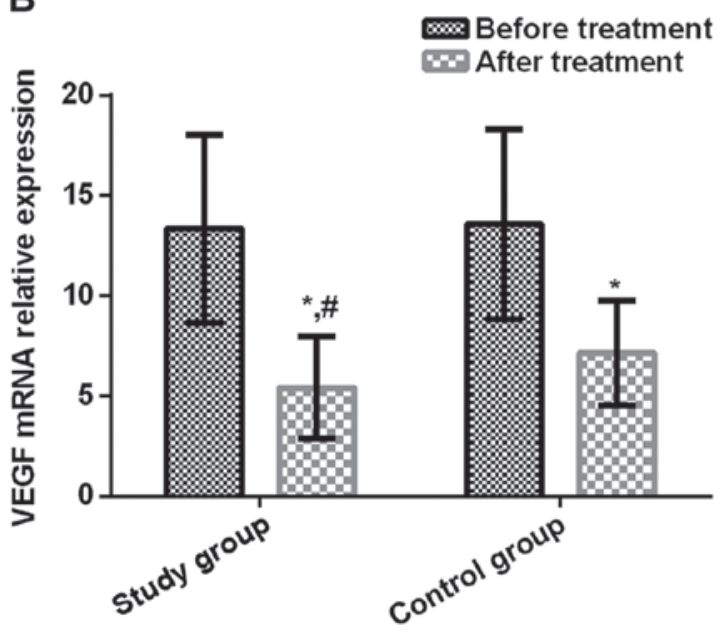

Figure 1. (A) Comparison of relative expression levels of serum DHFR mRNA before and after treatment in study group and control group. Results of RT-qPCR showed that there was no significant difference in the relative expression levels of serum DHFR mRNA before treatment between study group and control group ( $\mathrm{P}>0.05)$. In study group and control group, serum DHFR mRNA levels after treatment were significantly lower than those before treatment ( $\mathrm{t}=9.499$, $\mathrm{P}<0.001 ; \mathrm{t}=3.572, \mathrm{P}<0.001)$. After treatment, serum DHFR mRNA levels in study group were significantly lower than in control group $(\mathrm{t}=7.968, \mathrm{P}<0.001)$. $(\mathrm{B})$ Comparison of relative expression levels of serum VEGF mRNA before and after treatment in study group and control group. Results of RT-qPCR showed that there was no significant difference in the relative expression of serum VEGF mRNA before treatment between study group and control group ( $\mathrm{P}>0.05$ ). In study group and control group, serum VEGF mRNA levels after treatment were significantly lower than those before treatment $(\mathrm{t}=9.634$, $\mathrm{P}<0.001 ; \mathrm{t}=7.503$, $\mathrm{P}<0.001)$. After treatment, serum VEGF mRNA levels were significantly lower in study group than in control group $(\mathrm{t}=3.030, \mathrm{P}=0.003)$. $\mathrm{P}<0.001$, compared with before treatment level; ${ }^{~} \mathrm{P}<0.001$, compared with after treatment level in control group.

(55.00\%) and 10 cases of liver function impairment (25.00\%). There was no significant difference in the rate of thrombocytopenia and leukopenia during treatment between study group and control group $(\mathrm{P}>0.05)$. The rates of nausea and vomiting and liver function impairment during treatment in study group were significantly lower than those in control group $\left(\chi^{2}=4.843\right.$, $\mathrm{P}=0.044 ; \chi 2=4.897, \mathrm{P}=0.035$ ) (Table VI).
Changes of expression of serum DHFR mRNA and VEGF $m R N A$ before and after treatment in study group and control group. Relative expression levels of serum DHFR mRNA and VEGF mRNA before treatment in study group were (3.86 \pm 1.12$)$ and $(13.36 \pm 4.69)$, respectively, and those after treatment were $(2.05 \pm 0.52)$ and $(5.41 \pm 2.57)$, respectively. Those before treatment in control group were $(3.73 \pm 1.31)$ and $(13.57 \pm 4.73)$, 
respectively, and those after treatment were $(2.94 \pm 0.49)$ and (7.15 \pm 2.63$)$, respectively. There was no significant difference in the before treatment between study group and control group ( $\mathrm{P}>0.05)$. In study group and control group, relative expression level of serum DHFR mRNA after treatment was significantly lower than that before treatment $(\mathrm{t}=9.499, \mathrm{P}<0.001 ; \mathrm{t}=3.572$, $\mathrm{P}<0.001)$, and serum VEGF mRNA level after treatment was significantly lower than that before treatment $(t=9.634$, $\mathrm{P}<0.001 ; \mathrm{t}=7.503, \mathrm{P}<0.001)$. Relative expression levels of serum DHFR mRNA and VEGF mRNA after treatment in study group were significantly lower than those in control group $(\mathrm{t}=7.968, \mathrm{P}<0.001 ; \mathrm{t}=3.030, \mathrm{P}=0.003$ ) (Fig. 1).

\section{Discussion}

The basic treatment method for bladder cancer is radical cystectomy, which can prolong the overall survival of bladder cancer patients. However, surgical operations cause trauma. In addition, recurrence rate of some high-risk patients can reach $80 \%$ after surgery, thereby affecting the prognosis of patients (19). Postoperative metastasis and recurrence are major causes of poor treatment outcomes of bladder cancer. Thus, chemical drug treatment after surgery is usually needed (20). Chemotherapy drugs kill tumor cells, but they also damage the body's normal immune functions. In addition, development of drug-resistance will also reduce the efficacy of chemotherapy drugs (21). At present, the most widely used treatment method is GC chemotherapy regimen. With cytotoxic effects, gemcitabine and cisplatin can cause tumor cell death to control local tumor proliferation. As a result, the median survival and relapse-free survival rate of tumor patients are improved (22). Cognetti et al (23) showed that using GC chemotherapy regimen to treat invasive bladder cancer could improve the 5-year survival rate and diseasefree survival rate. Clinical anti-folic acid drug chemotherapy regimen is used in treatment of various malignant tumors, its resistance rate of single traditional anti-folic acid drug MTX is high, so it is often used in combination with other drugs such as cell cycle inhibitor (24). PTX, a small molecule anti-folic acid drug with a high affinity for reductive folic acid type I carrier protein, can increase tyrosine multimerization. It can also increase the drug uptake rate of cells and prolong the action time of drugs in tumor cells, so as to increase the drug concentration in them (25).

PTX is a targeted folic acid chemical for the treatment of chemotherapy-resistant or recurrent peripheral T-cell lymphoma that preferentially aggregates in tumor cells (26). CDK4/6, as an important regulatory protein involved in cell division cycle, can induce cell transformation from G1 phase to $\mathrm{S}$ phase. Inhibiting these two enzymes may block cell division (27). PAL, as a highly selective CDK4/6 inhibitor, can inhibit cells entering the $\mathrm{S}$ phase, cell growth and DNA replication (28). Results of this study showed that there was no significant difference in RR between study group and control group. After treatment, the concentration of ALT, AST, ALP, TBil in serum of the study group and the control group was significantly higher than those before treatment $(\mathrm{P}<0.05)$. The concentration of ALT, AST, ALP, TBil in the study group was significantly lower than that in the control group after treatment $(\mathrm{P}<0.05)$. The rates of nausea and vomiting and liver function impairment during treatment in study group were significantly lower than those in control group, suggesting that PTX combined with PAL has a better clinical efficacy in the treatment of bladder cancer patients. All the patients had some liver damage after chemotherapy, and PTX combined with PAL can kill cancer cells and reduce adverse reactions during treatment. During the progression of bladder cancer, tumor cells can synthesize various biological molecules and participate in the occurrence and development of bladder cancer (29). As a dihydrofolate (FH2) reductase, DHFR is capable of reducing dihydrofolateI level in the body. FH4, a carrier of one-carbon group, is involved in the synthesis of DNA (30).

Studies have shown that DHFR is highly expressed in drug-resistant tumor cells such as leukemia drug-resistant cells, breast cancer drug-resistant cells and osteosarcoma drug-resistant cells, and plays a role in multidrug resistance. With the increase of drug resistance in cells, DHFR expression significantly increases $(31,32)$. VEGF can induce vascular endothelial chemotaxis in vitro or in vivo, and is important for increasing the permeability of the vascular wall and maintaining the integrity of blood vessels. It can induce tumor neovascularization, which is conducive to the growth and infiltration of tumor cells (33). Hirata et al (34) showed that low-dose MTX can inhibit the proliferation of vascular endothelial cells in vitro and the neovascularization in vivo, suggesting that anti-folic acid drugs have a certain inhibitory effect on neovascularization in vivo. Results of this study showed that relative expression levels of serum DHFR mRNA and VEGF mRNA after treatment in study group and control group were significantly lower than those before treatment. After treatment, levels of serum DHFR mRNA and VEGF mRNA were significantly lower in study group than those in control group, suggesting that the mechanism of the actions of PTX combined with PAL in the treatment of bladder cancer patients is likely related to the suppressed tumor neovascularization, which is achieved by inhibiting the expression of DHFR and VEGF. Similar findings have been reported by Jocham et al (35). By regulating the expression of DHFR protein, PAL combined with PTX or MTX has a good effect on mantle cell lymphoma with or without p53 deficiency in blocking tumor cells in G1/S phase.

In this study, subjects were screened in strict accordance with the inclusion and exclusion criteria. There was no significant difference between study group and control group in general clinical baseline data such as sex, age, course of disease, histopathological type, pathological differentiation degree, tumor distribution location, clinical stage and the existence of distant metastasis, indicating the high reliability of this study. However, in this study, bladder cancer patients were included, so the regulatory mechanism of PTX combined with PAL on DHFRV, VEGF was not clarified. The clinicopathological parameters of bladder cancer patients are different from those of other malignant tumors, and there are some limitations on whether PTX combined with PAL is applicable to other malignant tumors. In future investigations, it is necessary to extend the research time, expand the category of malignant tumors, and carry out in vitro experiments to explore the mechanism of PTX combined with PAL in malignant tumors.

In conclusion, PTX combined with PAL can reduce adverse reactions of nausea and vomiting and liver function 
impairment during treatment. The mechanism of its actions may be related to the suppressed tumor neovascularization, which is achieved by inhibiting expression of DHFR and VEGF. PTX combined with PAL may become a new method for the treatment of bladder cancer patients. DHFRN and VEGF is expected to be a new biological therapy target for bladder cancer treatment.

\section{Acknowledgements}

Not applicable.

\section{Funding}

No funding was received.

\section{Availability of data and materials}

The datasets used and/or analyzed during the present study are available from the corresponding author on reasonable request.

\section{Authors' contributions}

XW collected the general information of patients. XW and HW were responsible for clinical efficacy evaluation. YS detected and analyzed the indicators. All authors read and approved the final manuscript.

\section{Ethics approval and consent to participate}

The study was approved by the Ethics Committee of Shengjing Hospital of China Medical University (Shenyang, China). Patients, who participated in this research, had complete clinical data. Signed written informed consents were obtained from the patients and/or guardians.

\section{Patient consent for publication}

Not applicable.

\section{Competing interests}

The authors declare that they have no competing interests.

\section{References}

1. Alfred Witjes J,Lebret T, CompératEM, Cowan NC, De Santis M, Bruins HM, Hernández V, Espinós EL, Dunn J, Rouanne M, et al: Updated 2016 EAU guidelines on muscle-invasive and metastatic bladder cancer. Eur Urol 71: 462-475, 2017.

2. Antoni S, Ferlay J, Soerjomataram I, Znaor A, Jemal A and Bray F: Bladder cancer incidence and mortality: a global overview and recent trends. Eur Urol 71: 96-108, 2017.

3. Arcangeli G, Strigari L and Arcangeli S: Radical cystectomy versus organ-sparing trimodality treatment in muscle-invasive bladder cancer: A systematic review of clinical trials. Crit Rev Oncol Hematol 95: 387-396, 2015.

4. Tekin A, Aki FT and Ozen H: Radical cystectomy versus alternative treatments for muscle-confined bladder cancer. Int Urol Nephrol 33: 357-362, 2001.

5. Kim HS, Jeong CW, Kwak C, Kim HH and Ku JH: Adjuvant chemotherapy for muscle-invasive bladder cancer: A systematic review and network meta-analysis of randomized clinical trials. Oncotarget 8: 81204-81214, 2017.
6. Tanino R, Tsubata Y, Harashima N, Harada M and Isobe T: Novel drug-resistance mechanisms of pemetrexed-treated non-small cell lung cancer. Oncotarget 9: 16807-16821, 2018.

7. Bhushan B, Ahuja D, Verma S, Saluja S, Siddiqui S and Kapur S: Relation of cell viability and apoptosis with clinical remission following induction chemotherapy in ALL and AML. J Exp Clin Cancer Res 26: 313-321, 2007.

8. Depau L, Brunetti J, Falciani C, Scali S, Riolo G, Mandarini E, Pini A and Bracci L: Coupling to a cancer-selective heparansulfate-targeted branched peptide can by-pass breast cancer cell resistance to methotrexate. Oncotarget 8: 76141-76152, 2017.

9. Marchi E, Mangone M, Zullo K and O'Connor OA: Pralatrexate pharmacology and clinical development. Clin Cancer Res 19: 6657-6661, 2013.

10. Nemoto A, Saida S, Kato I, Kikuchi J, Furukawa Y, Maeda Y, Akahane K, Honna-Oshiro H, Goi K, Kagami K, et al: Specific antileukemic activity of PD0332991, a CDK4/6 inhibitor, against Philadelphia chromosome-positive lymphoid leukemia. Mol Cancer Ther 15: 94-105, 2016.

11. Fawal MA, Jungas T, Kischel A, Audouard C, Iacovoni JS and Davy A: Cross talk between one-carbon metabolism, Eph signaling, and histone methylation promotes neural stem cell differentiation. Cell Rep 23: 2864-2873.e7, 2018.

12. Raghunathachar Sahana K, Akila P, Prashant V, Sharath Chandra B and Nataraj Suma M: Quantitation of vascular endothelial growth factor and interleukin- 6 in different stages of breast cancer. Rep Biochem Mol Biol 6: 33-39, 2017.

13. Chang SS, Boorjian SA, Chou R, Clark PE, Daneshmand S, Konety BR, Pruthi R, Quale DZ, Ritch CR, Seigne JD, et al: Diagnosis and treatment of non-muscle invasive bladder cancer: AUA/SUO guideline. J Urol 196: 1021-1029, 2016.

14. Mazza P, Moran GW, Li G, Robins DJ, Matulay JT, Herr HW, Decastro GJ, McKiernan JM and Anderson CB: Conservative management following clinical complete response to neoadjuvant chemotherapy of muscle invasive bladder cancer: Contemporary outcomes of a multi-institutional cohort study. J Urol: May 19, 2018 (Epub ahead of print).

15. Bell GC, Caudle KE, Whirl-Carrillo M, Gordon RJ, Hikino K, Prows CA, Gaedigk A, Agundez J, Sadhasivam S, Klein TE, et al: Clinical Pharmacogenetics Implementation Consortium (CPIC) guideline for CYP2D6 genotype and use of ondansetron and tropisetron. Clin Pharmacol Ther 102: 213-218, 2017.

16. Rittmeyer A, Barlesi F, Waterkamp D, Park K, Ciardiello F, von Pawel J, Gadgeel SM, Hida T, Kowalski DM, Dols MC, et al; OAK Study Group: Atezolizumab versus docetaxel in patients with previously treated non-small-cell lung cancer (OAK): A phase 3, open-label, multicentre randomised controlled trial. Lancet 389: 255-265, 2017.

17. Dueck AC, Mendoza TR, Mitchell SA, Reeve BB, Castro KM, Rogak LJ, Atkinson TM, Bennett AV, Denicoff AM, O'Mara AM, et al: Validity and reliability of the US National Cancer Institute's patient-reported outcomes version of the common terminology criteria for adverse events (PRO-CTCAE). JAMA Oncol 1: 1051-1059, 2015.

18. Perkins JR, Dawes JM, McMahon SB, Bennett DL, Orengo C, and Kohl M: ReadqPCR and NormqPCR: R packages for the reading, quality checking and normalisation of RT-qPCR quantification cycle (Cq) data. BMC Genomics 13: 296, 2012.

19. Mak RH, Hunt D, Shipley WU, Efstathiou JA, Tester WJ, Hagan MP, Kaufman DS, Heney NM and Zietman AL: Long-term outcomes in patients with muscle-invasive bladder cancer after selective bladder-preserving combined-modality therapy: A pooled analysis of Radiation Therapy Oncology Group protocols 8802, 8903, 9506, 9706, 9906, and 0233. J Clin Oncol 32: 3801-3809, 2014.

20. Soave A, Riethdorf S, Dahlem R, von Amsberg G, Minner S, Weisbach L, Engel O, Fisch M, Pantel K and Rink M: A nonrandomized, prospective, clinical study on the impact of circulating tumor cells on outcomes of urothelial carcinoma of the bladder patients treated with radical cystectomy with or without adjuvant chemotherapy. Int J Cancer 140: 381-389, 2017.

21. Qi X, Wong BL, Lau SH, Ng KT, Kwok SY, Kin-Wai Sun C, Tzang FC, Shao Y, Li CX, Geng W, et al: A hemoglobin-based oxygen carrier sensitized Cisplatin based chemotherapy in hepatocellular carcinoma. Oncotarget 8: 85311-85325, 2017.

22. Narayan V, Mamtani R, Keefe S, Guzzo T, Malkowicz SB and Vaughn DJ: Cisplatin, gemcitabine, and lapatinib as neoadjuvant therapy for muscle-invasive bladder cancer. Cancer Res Treat 48: 1084-1091, 2016 
23. Cognetti F, Ruggeri EM, Felici A, Gallucci M, Muto G, Pollera CF, Massidda B, Rubagotti A, Giannarelli D and Boccardo F; Study Group: Adjuvant chemotherapy with cisplatin and gemcitabine versus chemotherapy at relapse in patients with muscle-invasive bladder cancer submitted to radical cystectomy: An Italian, multicenter, randomized phase III trial. Ann Oncol 23: 695-700, 2012.

24. Cipolleschi MG, Marzi I, Rovida E, Olivotto $M$ and Dello Sbarba P: Low-dose methotrexate enhances cycling of highly anaplastic cancer cells. Cell Cycle 16: 280-285, 2017.

25. Gupta SC, Sung B, Prasad S, Webb LJ and Aggarwal BB: Cancer drug discovery by repurposing: Teaching new tricks to old dogs. Trends Pharmacol Sci 34: 508-517, 2013.

26. O'Connor OA, Hamlin PA, Portlock C, Moskowitz CH, Noy A, Straus DJ, Macgregor-Cortelli B, Neylon E, Sarasohn D, Dumetrescu O, et al: Pralatrexate, a novel class of antifol with high affinity for the reduced folate carrier-type 1, produces marked complete and durable remissions in a diversity of chemotherapy refractory cases of T-cell lymphoma. Br J Haematol 139: 425-428, 2007

27. Hydbring P, Malumbres $M$ and Sicinski P: Non-canonical functions of cell cycle cyclins and cyclin-dependent kinases. Nat Rev Mol Cell Biol 17: 280-292, 2016.

28. Toogood PL, Harvey PJ, Repine JT, Sheehan DJ, VanderWel SN Zhou H, Keller PR, McNamara DJ, Sherry D, Zhu T, et al: Discovery of a potent and selective inhibitor of cyclin-dependent kinase 4/6. J Med Chem 48: 2388-2406, 2005.

29. Knowles MA and Hurst CD: Molecular biology of bladder cancer: New insights into pathogenesis and clinical diversity. Nat Rev Cancer 15: 25-41, 2015.
30. Chen MJ, Shimada T, Moulton AD, Cline A, Humphries RK, Maizel J and Nienhuis AW: The functional human dihydrofolate reductase gene. J Biol Chem 259: 3933-3943, 1984.

31. Banerjee D, Mayer-Kuckuk P, Capiaux G, Budak-Alpdogan T, Gorlick R and Bertino JR: Novel aspects of resistance to drugs targeted to dihydrofolate reductase and thymidylate synthase. Biochim Biophys Acta 1587: 164-173, 2002.

32. Li S, Sun W, Wang H,Zuo D, Hua Y and Cai Z: Research progress on the multidrug resistance mechanisms of osteosarcoma chemotherapy and reversal. Tumour Biol 36: 1329-1338, 2015.

33. Poyet C, Thomas L, Benoit TM, Delmo DA, Luberto L, Banzola I, Günthart MS, Sais G, Eberli D, Sulser T, et al: Implication of vascular endothelial growth factor $\mathrm{A}$ and $\mathrm{C}$ in revealing diagnostic lymphangiogenic markers in node-positive bladder cancer. Oncotarget 8: 21871-21883, 2017

34. Hirata S, Matsubara T, Saura R, Tateishi H and Hirohata K: Inhibition of in vitro vascular endothelial cell proliferation and in vivo neovascularization by low-dose methotrexate. Arthritis Rheum 32: 1065-1073, 1989.

35. Jocham D, Witjes F, Wagner S, Zeylemaker B, van Moorselaar J, Grimm MO, Muschter R, Popken G, König F and Knüchel R: Improved detection and treatment of bladder cancer using hexaminolevulinate imaging: A prospective, phase III multicenter study. J Urol 174: 862-866, 2005.

This work is licensed under a Creative Commons Attribution-NonCommercial-NoDerivatives 4.0 International (CC BY-NC-ND 4.0) License. 